\title{
Phonological Differences between Received Pronunciation and Standard Scottish English
}

\author{
Ruilan $\mathrm{CaO}^{1, \text { a }}$, Shaokang $\mathrm{Jin}^{2, \mathrm{~b}, *}$ \\ ${ }^{1}$ School of Foreign Languages, Anhui University of Technology, Ma'anshan, P. R. China, 243032 \\ ${ }^{2}$ Division of Psychology and Language Sciences, University College London, London, UK, WC1E \\ 6BT

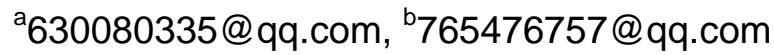

Keywords: accent, dialect, Phonology, Received Pronunciation, Standard Scottish English

\begin{abstract}
Native English speakers from different countries and regions use a variety of accents and dialects. English accents are part of English dialects. Any dialect of English has unique features in pronunciation, vocabulary and grammar. The term accent describes only the first of these, namely, pronunciation. In the UK, accents and dialects vary widely across its different regions. The aim of this paper is to explore phonological differences between Received Pronunciation and Standard Scottish English. Based on some collected speech data and application of speech analysis software Praat, their phonological distinctions are mainly discussed in vowels, consonants and prosody. The research on accents and dialects across the UK plays a critical role in the study of English Phonetics and Phonology. Investigating phonological differences between Received Pronunciation and Standard Scottish English is of great significance in English pronunciation education.
\end{abstract}

\section{Introduction}

The major native dialects of English are often divided by linguists into three general categories: the British Isles dialects, those of North America, and those of Australasia [1]. UK is one of the most accents and dialects obsessed nations in English speaking world. Countless accents and dialects have been shaped by its long and rich history. Among them are Received Pronunciation and Standard Scottish English. Received Pronunciation is the accent of Standard English in the UK. In the Concise Oxford English Dictionary, Received Pronunciation is defined as the standard accent of English as spoken in the south of England, although it can be heard from native speakers throughout England and Wales [2]. Standard Scottish English refers to the formal variety of English spoken in Scotland, and sometimes Standard English with a Scottish accent [3].

Received Pronunciation has been given particular prestige by sociolinguistic factors in parts of Britain [4]. It has been seen as the accent of those with power, wealth, and influence [5]. In Scotland, Standard Scottish English may be defined as the characteristic speech of the professional class and the accepted norm in schools [6]. With both Received Pronunciation and Standard Scottish English being given particular prestige in England and Scotland respectively, it is proper and necessary to explore distinctions between them. These two dialects differ in many aspects such as pronunciation, grammar, vocabulary as well as expressions, with their phonological distinctions being the most obvious. In this paper, their phonological differences are mainly discussed in vowels, consonants and prosody. Phonological study of English dialects and accents is of great significance in helping English learners especially foreign ones become more sensitive to different English varieties and acquire English speech better.

\section{Differences in Vowels}

There are a large number of vowel phonemes in English language, and these vowels differ considerably among dialects. Vowels of Received Pronunciation and Standard Scottish English differ significantly in terms of quantity and quality. 


\subsection{Vowel quantity}

One of the major realisational differences between Received Pronunciation and Standard Scottish English is the length of vowels. Vowel length of Received Pronunciation is phonemic, making length distinction contrast obvious. Unlike Received Pronunciation, vowel length of Standard Scottish English is allophonic and thus largely dependent on different contexts where vowels occur.

\subsubsection{Vowel length of RP}

In Received Pronunciation, short vowels include some of the monophthongs of $/ \mathrm{I} /, / \mathrm{J} / \mathrm{,} / \mathrm{e} / \mathrm{,} / \mathrm{\partial} /$, $/ \mathfrak{m} /, / \Lambda /$ and $/ \mathfrak{p} /$. Long vowels are the rest of the monophthongs $/ \mathrm{i}: /, / \mathrm{u}: /, / 3: /, / \mathrm{s}: /, / \mathrm{a}: /$, diphthongs of

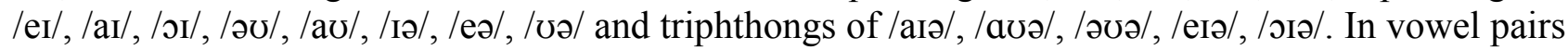
of Received Pronunciation, one is obviously longer than the other in comparable contexts such as beat /bi:t/ and bit /bIt/, bait /beit/ and bet /bst/, etc. Vowel length in Received Pronunciation is phonemic. /i:/ and /I/ differ in length with /i:/ being the longer one and /I/ being the shorter. This length distinction makes minimal pairs such as beat-bit and pool-pull available for that the vowels in beat and pool are longer than in bit and pull.

In Received Pronunciation, long and short vowels are relative to each other. Due to the phonological process affecting its vowel length, short vowels in one context can be longer than long vowels in another context [7]. The long vowel /i:/ in reach /ri:tf/ which ends with a voiceless consonant may be shorter than the short vowel /I/ in the word ridge /ridz/ which ends with a voiced consonant. Wiik (1965) published duration of English vowels with a mean value of $17.2 \mathrm{csec}$ for short vowels before voiced consonants but a mean value of $16.5 \mathrm{csec}$ for long vowels preceding voiceless consonants [8].

\subsubsection{Scottish Vowel Length Rule}

In Standard Scottish English, according to Scobbie et al., there are monophthongs of /i/, /I/, /a/, $/ \varepsilon /, / \mathrm{a} /, / \mathrm{o} /, / \mathrm{t} /, / \mathrm{o} /, / \mathrm{a} /, / \mathrm{\partial} /$ and $/ \Lambda /$, and three diphthongs of $/ \mathrm{aI} /, / \Lambda \mathrm{u} /$ and $/ \mathrm{oe} /[9]$. Unlike vowels in Received Pronunciation, there is no such a vowel length or tenseness contrast in Standard Scottish English. Thus the vowels in pairs like beat and bit are of the same length. And compared to vowels in Received Pronunciation, they are short. Vowels in Received Pronunciation can be distinct in both aspects of quality and quantity. But in Standard Scottish English, vowel phonemes are distinct in terms of quality alone.

Nevertheless, vowel length of Standard Scottish English is not quite simple. Unlike Received Pronunciation, vowel length of Standard Scottish English is not phonemic but largely allophonic, and therefore depends on the environment in which the vowels occur. The Scottish Vowel Length Rule (SVLR), also known as Aitken's Law, which was named after A. J. Aitken [10], the Scottish linguist who formulated it, refers to the general rule that certain vowels are long before /r/, voiced fricatives or a morpheme boundary. Thus the vowels in beer, breathe and agreed are longer than in bead, brief and greed. Aitken states that:

The vowels affected by the SVLR display a two-way variation between long duration in long environments and short duration in short environments, the regular long environments being: a following voiced fricative, $/ r /$ or a morpheme boundary, all of these either final or followed by a consonant constituting a second morpheme (Aitken, 1981).

Scottish Vowel Length Rule affects all vowels except $/ \mathrm{I} /$ and $/ \Lambda /$, which are always short in all contexts.

\subsection{Vowel quality}

In terms of vowel quality, differences between Received Pronunciation and Standard Scottish English are mainly demonstrated in monophthongs and diphthongs. 


\subsubsection{Monophthongs}

Unlike Received Pronunciation, Standard Scottish English has no / / phoneme, but a transcribed $/ \mathfrak{u} /$ realised as a high and usually rounded vowel which is central or even front. According to Wells, "from a diagnostic point of view, the most important characteristic of the Scottish Vowel system is its lack of phoneme /o/." [2] Therefore, in Received Pronunciation, words like pull and pool are pronounced differently as /pol/ and /pu:l/, but in Standard Scottish English they become homophones. Other examples include homophones like full and fool, and minimal pairs such as good and mood, puss and loose, etc.

In Received Pronunciation, words like cot and caught have different vowels $/ \mathrm{p} /$ and $/ \mathrm{o} /$. But there is no such a distinction in Standard Scottish English as it adopts / $/$ in both words, which makes some homophones available such as knotty and naughty, don and dawn, not and nought, etc. Certain speakers do distinguish between words of the LOT and the THOUGHT lexical sets but the opposition is not as systematic as that of RP speakers and thus, they may use $/ \mathrm{s} /$ instead of $/ \mathrm{p} / \mathrm{in}$ certain LOT words like yacht, wash, watch or squad [2].

As far as open vowels are concerned, Received Pronunciation has different /æ/-/a/ for words such as trap and bath. However, in most cases, there is no such distinction between $/ \mathfrak{x} /-/ \mathrm{a} /$ in Standard Scottish English, thus trap and bath have the same vowel /a/.

Nevertheless, what deserves our attention here is Bath vowel in Received Pronunciation. That is, trap-bath split did not happen in all eligible words of which some underwent the change and others did not. Generally, the more common a word is, the more likely that the change from flat /æ/ to /a:/ took place. There are also different opinions about whether /æ/ in the BATH lexical set can be considered as a vowel of RP. The pronunciations with /a:/ are generally accepted as RP [2]. As for /æ/, both the Longman Pronunciation Dictionary and The English Pronouncing Dictionary did not admit it in BATH words. Standard Scottish English is similar to Received Pronunciation in this regard. However, others argue that /æ/ in BATH lexical set should be considered within RP. Upton's Oxford Dictionary of Pronunciation for Current English gives both variants for BATH words.

In Standard Scottish English, a fairly centralized vowel $/ \varepsilon /$ has no equivalent in Received Pronunciation. It is often called Aitken's Vowel because it was Aitken who first discussed its phonetic quality. It is also often regarded as a floating vowel as the vowel is restricted in certain regions such as the West of Scotland, the Boarders and Edinburgh. Note that the vowel only occurs in stressed syllables like in words of never, seven, heaven, devil, etc.

The usual realization of the vowel / $\mathrm{I} /$ in Received Pronunciation is the same as in Standard Scottish English. However, in Standard Scottish English, /I/ may be more lowered and retracted in certain contexts. The variance of this phoneme is sensitive to class, which has been researched in Edinburgh [11] and Glasgow in the 1970s [12] and again in the 1990s [13]. In all cases it showed that lower-class speakers used lower and more retracted variants than those of higher-class speakers.

An unstressed word-final vowel/I/ in Received Pronunciation becomes /e/ in Standard Scottish English (e.g. in happy, baby, lady).

In words like comma, the vowel in Received Pronunciation is / /. According to Wells [2], not every version of Standard Scottish English has /ə/. Instead of /ə/, Standard Scottish English usually has $/ \mathrm{N}$, though in many cases it is realized as $/ \mathrm{I} /$, such as in pilot $/$ paelit/. 


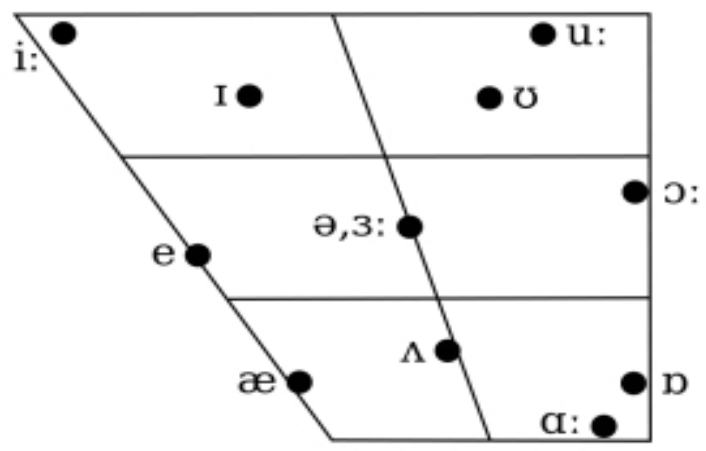

Figure 1: Monophthongs of RP from Roach (2004: 243)

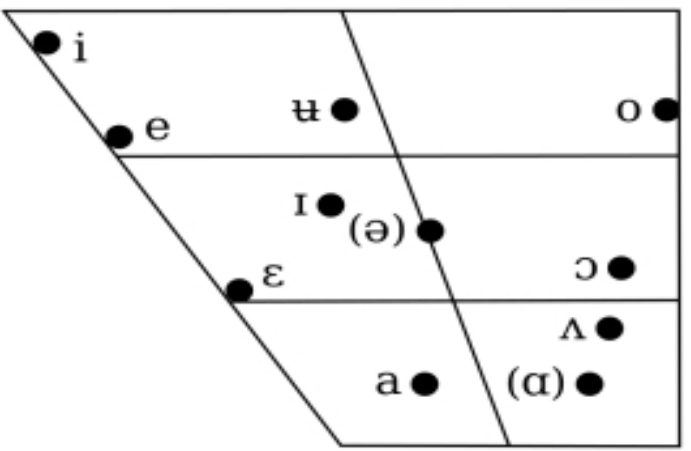

Figure 2: Monophthongs of SSE from Scobbie et al. (2006: 6)

\subsubsection{Diphthongs}

The diphthong /ai/ in words such as prize and price in Received Pronunciation could become /ae/ or $/ \Lambda \mathrm{i} /$ in Standard Scottish English. In the case of the /ae/-/ $\mathrm{i} /$ alteration, /ae/ behaves as the long variant of $/ \Lambda \mathrm{i} /$ [14]. The first, /ae/ occurs before /r/, a voiced fricative or a morpheme boundary such as in words fire/'faer/, prize /praez/ and tried /traed/. The other one $/ \Lambda \mathrm{i} /$ is used in other circumstances such as in words price /pruiz/ and side /s $\Lambda \mathrm{id} /$. The /ae/-/ $\mathrm{i} /$ alteration and above examples are also in accordance with Scottish Vowel Length Rule.

The diphthong in Received Pronunciation /av/ is centralized as / $\Lambda \mathrm{u} /$ in Standard Scottish English. Thus in words like out and house, the vowel is $/ \Lambda \mathrm{t} /$. However, there is considerable social linguistic variation that working-class speakers in Scotland use Scots variant $/ \mathfrak{u} /$ in out and house words, while middle-class speakers in Scotland avoid this Scots variant. The selection of the Scots vowel $/ \mathfrak{u} /$ in a word like house tends to correlate with social stratification [13].

In Received Pronunciation, the diphthong involved in words like boy and voice is /pi/. The usual realization of the corresponding diphthong in Standard Scottish English is /oe/. However, there can be different variants of its transcription such as /oi/ [2], /oe/ [15] and /oe/ [9]. Brigitta Fodor thought that the exact quality of this diphthong is probably variable Scottish speech, but/oe/ seems to be a good compromise between reported surface forms [14].

The vowel in face words in Received Pronunciation is diphthong /eI/. However, the corresponding vowel in Standard Scottish English is monophthongized as /e/. Similarly, Standard Scottish English has a monophthong /o/ corresponding to the Received Pronunciation /əv/. Therefore, words like face and pace are pronounced as /fes/ and /pes/, and goat and coat/got/ and /kot/. Brigitta Fodor thought that some Scots dialects distinguish a long version of these two sounds, but this long version is mostly lost according to the Scottish Vowel Length Rule [14].

\section{Differences in Consonants}

Differences between Received Pronunciation and Standard Scottish English in terms of consonants are not as distinctive as in vowels, and their differences in this aspect are mainly discussed in rhoticity, plosives and fricatives.

\subsection{Rhoticity}

Rhoticity in English refers to the situations in which the historical rhotic consonant $/ \mathrm{r} /$ is pronounced. It is one of the most prominent factors that distinguish English varieties. In rhotic varieties of English, speakers pronounce $/ \mathrm{r} /$ in all instances, while in non-rhotic varieties, speakers do not pronounce $/ \mathrm{r} /$ in postvocalic environments when it is immediately after a vowel and not followed by another vowel [16].

One of the major differences between Received Pronunciation and Standard Scottish English is 
that the former one is non-rhotic and the later one belongs to rhotic variety.

\subsubsection{Non-rhotic RP}

Received Pronunciation speakers do not pronounce $/ \mathrm{r} /$ in postvocalic environments where it is after a vowel and not followed by another vowel. Therefore, pairs such as farther/father, source/sauce and formally/formerly in Received Pronunciation are homophones. Non-rhotic speakers of Received Pronunciation still pronounce $/ \mathrm{r} /$ in syllable-initial and intervocalic positions such as in words ready and barrel, and in the phenomenon of Linking $R$ in which a word ending in written " $r$ " is followed closely by a word beginning with a vowel-as in water ice.

\subsubsection{Rhotic SSE}

Standard Scottish English is a rhotic accent, which means that $/ \mathrm{r} /$ is typically pronounced in the syllable coda. The phoneme $/ \mathrm{r} /$ could be an alveolar approximant $/ \mathrm{r} /$, alveolar tap $/ \mathrm{f} /$ or alveolar trill $/ \mathrm{r} /$. Trills are now unusual, and Stuart-Smith states that she certainly has rarely heard them amongst Scottish English students [15]. More usual are approximants, retroflex and alveolar taps, which vary according to position in the word, phonetic environment and social linguistic environments [15]. Scots are usually said to favor taps, though Johnston notes that $/ \mathrm{I} /$, more typical of Standard Scottish English, is encroaching [17].

\subsubsection{Historic reasons for this rhotic distinction}

The difference in rhoticity between Received Pronunciation and Standard Scottish English was explained by John Wells claiming that Standard Scottish English has not undergone changes of Pre-R Breaking, Pre-Schwa Laxing and R Dropping that Received Pronunciation has [2].

First, Pre-R Breaking refers to the epenthesis of a schwa between the vowels /i:/, /e:/, /u:/ and the following /r/. Therefore in Received Pronunciation, words like beer, chair and sure were pronounced from /bi:r/, /t $\int$ e:r/, / $/$ u:r/ to /bi:ər/, /t $\int$ e:ər/, $/ \int \mathrm{u}: ə r /$ Then, Pre-Schwa Laxing involves

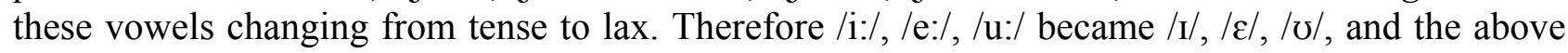
words were pronounced /bır/, / $\mathrm{t}$ cər/, / Jər/. And finally $R$ Dropping refers to the missing of $/ \mathrm{r} /$ before a consonant or in absolute final position. Thus the three words are pronounced as /brə/, / $\mathrm{t} \int \varepsilon ə /$, / Joə/. Standard Scottish English has not undergone these changes so that it still preserves the historical consonant $/ \mathrm{r} /$, making it a rhotic accent.

\subsection{Plosives}

Compared to Received Pronunciation, plosives in Standard Scottish English are generally reported to be less aspirated [2]. Further difference in this aspect is discussed in terms of glottal stop.

\subsubsection{Aspiration}

In Received Pronunciation, voiceless plosives $/ \mathrm{p} /, / \mathrm{t} /$ and $/ \mathrm{k} /$ are aspirated at the beginning of a syllable, unless followed by a completely unstressed vowel or with $/ \mathrm{s} /$ preceding them in the same syllable. For example, the $/ \mathrm{p} /$ is aspirated in pass, but not in compass or spot.

Compared with Received Pronunciation, plosives $/ \mathrm{p} /, / \mathrm{t} /, / \mathrm{k} /$ in Standard Scottish English are generally not aspirated. Nevertheless, this is not always the case as the aspiration is often common in speakers of middle class. Stuart-Smith stated that aspiration was shorter with a working class person [15]; however, the middle class speaker had a considerable amount of aspiration with voiceless stops. Also speakers from Glasgow aspirate the stops [18]. 


\subsubsection{Glottal stops}

In Received Pronunciation, /p/, /t/, and / $/$ in final syllables may be either preceded by a glottal reinforcement or in the case of /t/ fully replaced by a glottal stop, especially before a syllabic nasal like the word bitten /'bi?n/.

In Standard Scottish English, non-initial /t/ comes with / $/$ / glottalization. Thus the word like sentimental is pronounced /'sen?I'men?1/. Glottal reinforcement to /p/ and / $\mathrm{k} /$ can also occur in the same environment. The t-glottaling in Standard Scottish English can differ in social class distinction. Neroldova states that it is typical for the lower class, optional with the middle class, and restricted with the upper class speakers [18].

\subsection{Fricatives}

In terms of consonants, slight differences between Received Pronunciation and Standard Scottish English are usually found in dental fricatives $/ \theta /$ and $/ ð /$, alveolar fricatives $/ \mathrm{s} /$ and $/ \mathrm{z} /$ as well as velar fricative $/ \mathrm{x} /$.

\subsubsection{Dental fricatives}

As dental fricatives, $/ \theta /$ and /ð/ are pronounced the same in Received Pronunciation and Standard Scottish English. However, in plural nouns like youths and baths, Received Pronunciation has /ðz/ while Standard Scottish English often uses $/ \theta \mathrm{s} /$.

In Urban Scots $/ \theta /$ has the traditional variant $/ \mathrm{h} / \mathrm{such}$ as in think, which may also be completely deleted such as in the word both [15]. In Standard Scottish English, the voiced dental fricative /ð/ is often changed into tap / $\mathrm{f} /$ especially in intervocalic positions such as in the word brother, though complete elision is also common [15]. Stuart-Smith also states that the working-class adolescents in the 1997 Glasgow sample showed /v/ for /ð/ in words such as smooth [15].

\subsubsection{Alveolar fricatives}

/s/ and /z/ are also the same in both Received Pronunciation and Standard Scottish English in which speakers can have a distinctive articulation of them.

However, in Standard Scottish English, /s/ can be changed into /z/ in voicing assimilation, which is an interesting phenomenon occurring time to time in Scottish English [2]. For example, the phrase most valuable is transcribed as /moz 'valjəbl/. The consonant /s/ in most changes into voiced sound $/ z /$ under the influence of the following voiced fricative. The t-elision is perceptible at the end of a word which is followed by another word beginning with a voiced sound [18].

\subsubsection{Velar fricative /x/}

Voiceless velar $/ \mathrm{x} /$ is not generally found in southern accents of English and Received Pronunciation [2]. But it is included in consonant inventory of Standard Scottish English. It often appears in word-final and word-central positions with ch spelling such as in the words loch and technical. This phoneme is typically used in certain names and standard Scottish English's many Gaelic and Scots borrowings. Some Scottish speakers use it in words of Greek origin as well, such as technical, patriarch, etc. [2].

Although / $\mathrm{x} /$ is still very important for many speakers of Standard Scottish English, the younger generation of Scottish speakers would have difficulties to even come up with some words that would include this phoneme [19].

\subsubsection{Consonant cluster /hw/}

Consonant clusters of Received Pronunciation and Standard Scottish English are generally alike, 
but in Standard Scottish English, onset /hw/ is still common in wh words [9]. So there is a distinction between /w/ and / hw/ in word pairs such as witch and which in Standard Scottish English.

The pairs such as witch and which, Wales and whales are considered as homophones in Received Pronunciation but minimal pairs in Standard Scottish English. Some scholars refer to this phoneme as a unique segment in Standard Scottish English consonant inventory, while others analyzed it as a consonant cluster $/ \mathrm{hw} /$. In this paper, this phoneme in Standard Scottish English is analyzed as a consonant cluster of $/ \mathrm{h} / \mathrm{plus} / \mathrm{w} /$.

\section{Differences in Prosody}

Different accents of English and any other languages often have some of their own prosodic features. In the field of linguistics, prosodic features are concerned with those elements of speech that are not individual phonetic segments (vowels and consonants) but are properties of syllables and larger units of speech, such as intonation, tone, stress, and rhythm. In this part, differences in prosody between Received Pronunciation and Standard Scottish English are mainly discussed in aspects of stress, intonation and rhythm.

\subsection{Stress}

Wells states that the stress pattern varies across English accents only with minor differences, otherwise, the underlying principle traverses each English accent [2].

Received Pronunciation and Standard Scottish English bear some differences in word stress. Received Pronunciation tends to stress the first syllables in verbs suffixed by -ize. Therefore, in the following words: advertize, baptize, realize and recognize, the primary stress in Received Pronunciation falls on the first syllables while in Standard Scottish English it is on the final syllables.

In words of porpoise and tortoise, the main stress lies on the first syllables in Received Pronunciation, while Standard Scottish English have equal stress on each syllable. Besides, words like lamentable and preferably have the primary stress on the first syllables in Received Pronunciation and on the second syllables in Standard Scottish English.

Nevertheless, both Received Pronunciation and Standard Scottish English distinguish between verbs and nouns by stressing the second syllable in the case of a verb and on the first syllable in the case of a noun [2]. Thus in words like present and record, both Received Pronunciation and Standard Scottish English have the second stressed syllable in case of being verbs and the first stressed syllable in case of being nouns.

\subsection{Intonation}

Received Pronunciation has a distinctive, clear intonation with a noticeable tendency for high-falling patterns. It is particularly common among younger speakers to use lengthened vowels and creaky voice towards the end of a sentence or tone unit. This might because younger speakers of Received Pronunciation especially female ones have been influenced more by American culture in which lengthened vowels and creaky voice are prevalent as a peer-group affectation among young women [20].

Apart from the work of Brown and his colleagues on Edinburgh intonation, there has been surprisingly little research on intonation of Scottish English [15].

The intonation of Scottish English often shows obvious regional variability. For accents of Scotland other than those found in Glasgow, statements and questions will invariably show "a sequence of falling tones" [21]. Rising tones are reported for many northern cities, for example in Glasgow [22]. The main difference between the speech of Edinburgh and Glasgow is in terminating mid-to-low falls in Edinburgh but a tendency towards high rising patterns in Glasgow [15]. 
Northern Irish influence may be invoked to some extent to explain distinctive Glaswegian patterns [15].

Some audio data samples of Received Pronunciation and Standard Scottish English (Edinburgh and Glasgow speech) were selected in order to analyze their intonation distinctions with the application of Praat. From the figures we can see that Received Pronunciation shows an obvious tendency of high-falling patterns, while Standard Scottish English demonstrates great variability in its intonation (see Figure 3, 4 and 5).
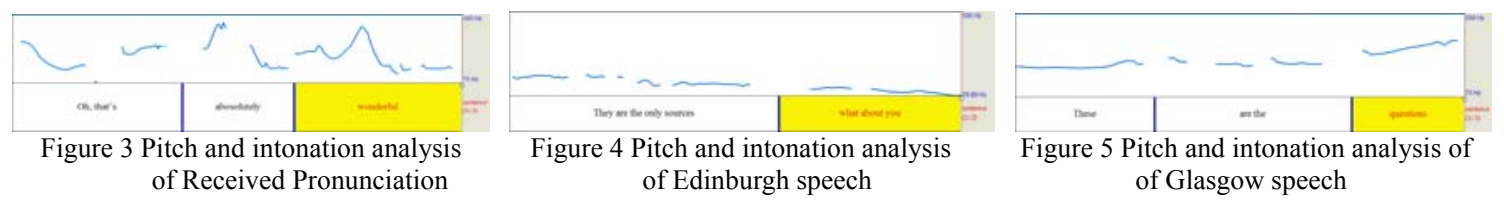

\subsection{Rhythm}

Cruttenden understands the term rhythm as the extent to which there is a regular beat in speech [22]. Rhythm is certainly one of factors which differentiate accents [23]. Received Pronunciation is spoken with what is known as a stress-timed rhythm, which means that the stressed, or salient syllables tend to recur at roughly equal intervals of time. It is quite different from many other languages which are regarded as syllable-timed ones in which all the syllables recur at roughly equal intervals of time [18].

The distinct rhythm of Standard Scottish English is what is known as Scottish snap-in disyllabic words one syllable is long and the other is short. Disyllabic words such as table are often pronounced with a short first syllable and a long second syllable [23]. This has something to do with word stress patterns of Standard Scottish English, as a stress pattern of a language is probably the most crucial factor influencing rhythm [2].

Syllabification in Standard Scottish English can be different from that in Received Pronunciation. This difference is often seen in phrasal verbs. In Received Pronunciation, the consonant tends to be placed with the stressed syllable. In Standard Scottish English, syllabification tends to favor open syllables - a consonant at the end of one word in a closed syllable tends to be syllabicated with the following vowel of the subsequent word. Therefore a phrase such as St Andrews will be syllabified into /sn tan druz/ [15], and phrases of an aim and a name bear the same syllabification in Standard Scottish English with both bearing / .nem/.

Some audio data samples of Received Pronunciation and Standard Scottish English selected from a BBC program and a Scottish interview were used to analyze their differences seen in rhythm. The two figures show that rhythm of Received Pronunciation is quite regular with the stressed, or salient syllables tending to recur at roughly equal intervals of time, while rhythm of Standard Scottish English is not as regular as that of Received Pronunciation due to the effect of Scottish snap (see Figure 6 and 7).

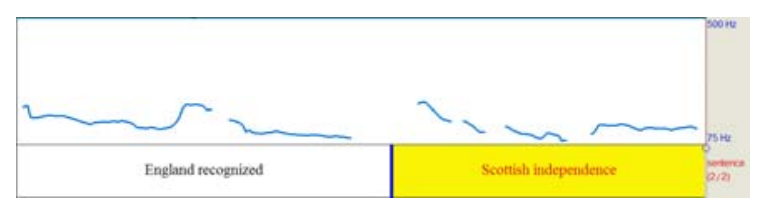

Figure 6 Audio data analysis of Received Pronunciation

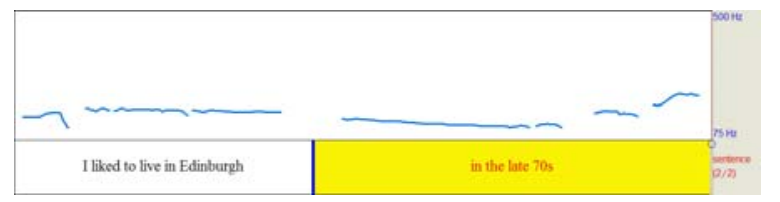

Figure 7 Audio data analysis of Standard Scottish English

\section{Conclusion}

Great variation often occurs across areas where English is spoken as the first language. In the UK, it makes sense to compare Received Pronunciation and Standard Scottish English in terms of phonology, because they differ distinctively in their phonological features and inventories, and both 
enjoy a certain prestige in England and Scotland respectively being favored by speakers of middle and upper classes.

In this paper, phonological differences between Received Pronunciation and Standard Scottish English are mainly discussed in aspects of vowels, consonants and prosody, with their distinctions in vowels being the most obvious. Firstly the vowel inventories of Received Pronunciation and Standard Scottish English are compared to explore their specific distinctions in vowel length, monophthongs and diphthongs. Then in terms of consonants, the most prominent difference between the two is mainly seen in rhoticity with Received Pronunciation being non-rhotic and Standard Scottish English rhotic. Some other distinctions are also discussed in their plosives and fricatives. Apart from vowels and consonants, several prosodic features of stress, intonation and rhythm in Received Pronunciation and Standard Scottish English are explored finally. More data collection and analysis remain the major task of further research.

\section{Acknowledgements}

This paper has been supported by National Social Science Foundation of China (Project No. 15BYY024), by National Natural Science Foundation of China (Project No. 71272220 and Project No.71572002), by Key Teaching Reform Project of Anhui Province (2015zdjy067), by Excellent University Youth Talents Supporting Program of Anhui Province, China (Anhui Education Personnel [2014] Reference No.: 181).

\section{References}

[1] Crystal, D. 2003. The Cambridge Encyclopedia of the English Language. Cambridge: Cambridge University Press.

[2] Wells, J.C. 1982 Accents of English 2: The British Isles. Cambridge: Cambridge University Press.

[3] Wells, J.C. 2008. The Longman Pronunciation Dictionary. Pearson Longman.

[4] Hudson, R. 1981. Some issues on which linguists can agree. Journal of Linguistics, 17 (2): 333-343.

[5] Crystal, D. 2007. A Dictionary of Linguistics and Phonetics. London: Blackwell Publishing.

[6] McClure, J.D. 1994. English in Scotland. Cambridge: Cambridge University Press.

[7] Roach, P. 2004. British English: Received Pronunciation. Journal of the International Phonetic Association, 34 (2): 239-245.

[8] Wiik, K. 1965. Finnish and English Vowels. Turku: University of Turku.

[9] Scobbie, J.M., Gordeeva, O.B. \& Matthews, B. 2006. Acquisition of Scottish English Phonology: an overview. Edinburgh: QMU Speech Science Research Centre Working Papers.

[10] Aitken, A.J. 1981. The Scottish Vowel-Length Rule. Edinburgh: Middle English Dialect Project.

[11] Johnston, P. \& Speitel, H. 1983. A sociolinguistic investigation of Edinburgh speech. Final Report to the ESRC.

[12] Macaulay, R. 1977. Language, Social Class and Education: A Glasgow Study. Edinburgh: Edinburgh University Press.

[13] Stuart-Smith, J. 1999. Glasgow: Accent and Voice Quality. Urban voices: Accent studies in the British Isles: 203-222. London: Arnold.

[14] Fodor, B. 2014. Scottish vowel length: Regular vowel length alternations and the raising of /ae/ in Scottish Standard English. The Odd Yearbook.

[15] Stuart-Smith, J. 2008. Scottish English: Phonology. A Handbook of Varieties of English, (1): 47-67. Berlin: DE GRUYTER MOUTON. 
[16] Skandera, P. \& Burleigh, P. 2011. A Manual of English Phonetics and Phonology. Tubingen: Gunter Narr Verlag.

[17] Johnston, P. 1997. Regional Variation. In Charles Jones (ed.), The Edinburgh history of the Scots language, 433-513. Edinburgh: Edinburgh University Press.

[18] Neroldova, V. 2013. Standard Scottish English: An illustration for journals of the International Phonetic Alphabet. Journal of the International Phonetic Association, 25 (6): 5-56.

[19] Scobbie, J.M. \& Stuart-Smith, J. 2006. Quasi-phonemic Contrast and the Fuzzy Inventory: Examples from Scottish English. QMUC Speech Science Research Centre Working Paper WP-8.

[20] Yuasa, I. 2010. "Creaky voice: A new feminine voice quality for young urban-oriented upwardly mobile American women?”. American Speech 85 (3): 315-337.

[21] Cruttenden, A. 1997. Intonation. Cambridge: Cambridge University Press.

[22] Cruttenden, A. 2008. Gimson's Pronunciation of English. London: Hodder Education.

[23] Abercrombie, D. 1979. The Accents of Standard English in Scotland. Edinburgh: Chambers. 